\title{
Level of Empathy in Nursing Students Attending Clinical Practices of the Universidad de Ciencias y Humanidades
}

Walter Cervera-Flores ${ }^{1}$, Yenifer Choque-Garibay ${ }^{1}$, Nahuel Gonzalez-Cordero ${ }^{1}$, Brian Meneses-Claudio ${ }^{2,}$, , Hernan Solis-Matta $^{1}$, Lourdes Matta-Zamudio ${ }^{1}$

${ }^{1}$ Faculty of Health Sciences, Universidad de Ciencias y Humanidades, 15314, Lima-Perú

${ }^{2}$ Image Processing Research Laboratory (INTI-Lab), Universidad de Ciencias y Humanidades, 15314, Lima-Perú

A R T I C L E IN F O

Article history:

Received: 03 August, 2020

Accepted: 25 December, 2020

Online: 15 January, 2021

Keywords:
Empathy
Nursing students
Clinical practices
Compassionate care
Professional training

\section{Introduction}

Empathy in patient care for nursing students is a cognitive attribute that implies the ability to understand pain, suffering and the patient's perspective, it is the ability to stablish this understanding and the intention to help [1].

Nursing students must be empathetic and this is governed based on their behavior, this will be influenced in the well-being of themselves and also of the patient [2].

Empathy depends on the personality and functional characteristics of the nurse so that the nursing student has a good performance in their study plan [3]. Therefore, there are numerous exploration methods that have been designed in educational programs to improve empathy [4]. In addition, empathy is attributed to factors that influence the nursing student such as interpersonal relationships, self-esteem, communication, and self-efficacy [5].

In [6], the authors explain a study carried out in Spain, it was found that technological advance acts on empathy in nursing

${ }^{*}$ Corresponding Author: Brian Meneses-Claudio, bmeneses@uch.edu.pe professionals, leading to a lack of interest in interaction with patients.

In [7], the authors presented a study carried out in Venezuela, it was observed in the results that $90.1 \%$ of the nursing students were women and those who obtained a higher score in level of empathy.

In [8], the authors described a study carried out in Canada, they stated in their results that the instructional and practice sessions increased students' self-awareness about prejudices and interest in learning empathy through video tag feedback.

This study is important since it will give relevant and real data about empathy as students go in their academic plan and, observe if they can have an empathetic attitude when they carry out their activities in the clinical practical field.

The following research work is structured as follows: In section II, the development of the data collection process of each nursing student will be presented, as well as the guidelines to consider so that they are within the research work. In section III, the results will show the level of empathy that nursing students 
will present according to the specified dimensions of the instrument in the measurement of the variable. In section IV, it presents the discussions of the research work, in section $\mathrm{V}$, the conclusions and in section VI the recommendations as well as the future work that is intended to come with the research work.

\section{Methodology}

\subsection{Materials and Methods}

In this part, the type and design of the research will be developed, as well as the population and sample that will be carried out in the research work, the inclusion and exclusion criteria in detail and finally the technique and the instrument of collection of data.

\subsection{Research type and Design}

It is a study with a quantitative approach, a nonexperimental, descriptive and cross-sectional design [9].

\subsection{Population}

The population was 289 nursing students from the Universidad de Ciencias y Humanidades.

\subsubsection{Inclusion Criteria}

Nursing students who are in the third semester until the eighth semester and who have signed the informed consent that was evaluated and approved by the ethics committee of the Universidad de Ciencias y Humanidades.

\subsection{Technique and Instrument}

In the study, the data collection instrument Escala de Empatía Médica de Jefferson (EEMJ) from Hojat Mohammandreza was applied, which has been demonstrated to be useful in assessing level of empathy in nursing students.

The JSE instrument is a shortened and derived tool of the Escala de Empatía Médica de Jefferson, which consists of 20 questions developed in parallel in more than 85 countries and translated into 56 languages.

To measure empathy, the instrument Escala de Empatía Médica de Jefferson (EEMJ) from Hojat Mohammandreza, which includes 20 items grouped in 3 dimensions, will be used: perspective taking, compassionate care and ability to put oneself in the patient's place where they are governed by the high, medium, and low levels according to the instrument manual. The answers will have two significant frames for each of the items, if it disagrees it is 0 and if there is agreement it is valued at 7 , with a variation score of 20 to 140 . Between 20 to 60 refers to low empathy, of 61 to 100 refers to medium empathy and 101 to 140 refers to high empathy [10].

\subsection{Place and Application of the Instrument}

The questionnaire was carried out in two consecutive schedules, morning, and night at the same time as the nursing students who practice at the university, the questionnaire was taken to the nursing students with an approximate time of 15 minutes each selected semester (III semester to VIII semester according to inclusion criteria) in the research work, concluding with good satisfaction when collecting the questionnaires as the students provided support to carry out the research work.

The data collection was processed through the survey of nursing students, the data was carried out in a data matrix that will be designed in the statistical program SPSS (Statistical Package for the Social Sciences) in its version 24.0, in which it will allow a better data processing to make statistical tables and graphs so that they can then be described and interpreted in results and discussions, respectively.

It is important to emphasize the presence of medical personnel at the time of completing the student questionnaire, since most of them presented signs of having a health problem.

\section{Results}

Regarding empathy in nursing students who carry out preprofessional practices at the Universidad de Ciencias y Humanidades it can see that 210 participants represent $72.7 \%$ with a medium level of empathy, followed by 74 participants who represent $25.6 \%$ with a high level of empathy and 5 participants representing $1.7 \%$ with a low level of empathy.

Table 1: Level of Empathy in Nursing Students attending Clinical Practices of the Universidad de Ciencias y Humanidades, $2019(\mathrm{~N}=289)$

\begin{tabular}{|c|c|c|c|c|c|}
\hline \multicolumn{6}{|c|}{ Empathy } \\
\hline & & $\begin{array}{l}\text { Fre } \\
\text { que } \\
\text { ncy }\end{array}$ & $\begin{array}{l}\text { Perce } \\
\text { ntage }\end{array}$ & $\begin{array}{l}\text { Valid } \\
\text { percenta } \\
\text { ge }\end{array}$ & $\begin{array}{l}\text { Accumul } \\
\text { ated } \\
\text { percenta } \\
\text { ge }\end{array}$ \\
\hline \multirow{4}{*}{$\begin{array}{l}\text { V } \\
\text { a } \\
\text { li } \\
d\end{array}$} & Low & 5 & 1,7 & 1,7 & 1,7 \\
\hline & $\begin{array}{l}\text { Mediu } \\
\text { m }\end{array}$ & 210 & 72,7 & 72,7 & 74,4 \\
\hline & High & 74 & 25,6 & 25,6 & 100,0 \\
\hline & Total & 289 & 100,0 & 100,0 & \\
\hline
\end{tabular}

These results indicate that the students present a medium empathy, because many of them possess skills that would demonstrate high empathy, however, they have the difficulty of expressing or manifesting what another person may experience, in which they cannot to be developed without having the adequate knowledge, for this, they seek solutions either at an academic or practical level in which they can complement that space, in order to be able to develop their skills and have the greatest capacity for evaluation in what another person may experience.

In the Figure 1 shown, the results regarding the dimensions of empathy are evidenced according to the data based on the research instrument:

In Figure 1, it can see the empathy according to its dimensions, in nursing students who attend clinical practices of the Universidad de Ciencias y Humanidades, where the dimension most affected was the compassionate care where 130 students representing $45 \%$ have low empathy. This dimension has been the most affected, although it is true it is related to patient care, however, it has been proven that the same patients 
attribute that their care is not adequate, that they are not provided with compassionate care, for the Nursing students, this dimension assumes an important role due to the fact that the students are in full training, that compassionate care is very important, for this, education at an academic or practical level, it is necessary to distinguish a very important role on compassion, due to this fundamental role is being lost in nursing students due to the lack of interventions on understanding compassionate care for the patient.

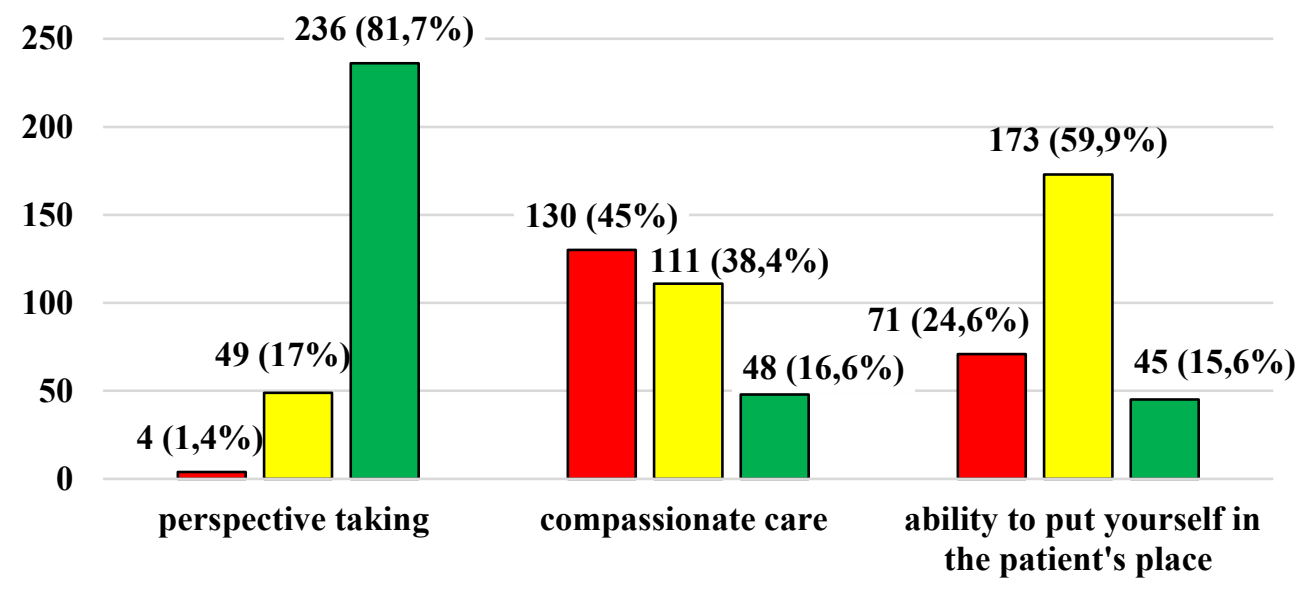

$\square$ low empathy $\square$ medium empathy $\square$ high empathy

Figure 1: Empathy according to its dimensions, in nursing students attending clinical practices at the Universidad de Ciencias y Humanidades, 2019 ( $\mathrm{N}=289)$.

Table 2: Empathy in relation to the Semester of study of Nursing Students who attend in clinical practices of the Universidad de Ciencias y Humanidades, 2019 $(\mathrm{N}=289)$

\begin{tabular}{|c|c|c|c|c|c|c|}
\hline & & & \multicolumn{3}{|c|}{ Empathy } & \multirow[t]{2}{*}{ Total } \\
\hline & & & Low & Medium & High & \\
\hline \multirow[t]{12}{*}{ STUDY SEMESTER } & \multirow{2}{*}{$\begin{array}{l}\text { III } \\
\text { SEMESTER }\end{array}$} & Count & 0 & 61 & 16 & 77 \\
\hline & & $\%$ within the Semester & $0,0 \%$ & $79,2 \%$ & $20,8 \%$ & $100,0 \%$ \\
\hline & \multirow{2}{*}{$\begin{array}{l}\text { IV } \\
\text { SEMESTER }\end{array}$} & Count & 3 & 25 & 9 & 37 \\
\hline & & $\%$ within the Semester & $8,1 \%$ & $67,6 \%$ & $24,3 \%$ & $100,0 \%$ \\
\hline & \multirow{2}{*}{$\begin{array}{l}\text { V } \\
\text { SEMESTER }\end{array}$} & Count & 0 & 47 & 10 & 57 \\
\hline & & $\%$ within the Semester & $0,0 \%$ & $82,5 \%$ & $17,5 \%$ & $100,0 \%$ \\
\hline & \multirow{2}{*}{$\begin{array}{l}\text { VI } \\
\text { SEMESTER }\end{array}$} & Count & 0 & 34 & 16 & 50 \\
\hline & & $\%$ within the Semester & $0,0 \%$ & $68,0 \%$ & $32,0 \%$ & $100,0 \%$ \\
\hline & \multirow{2}{*}{$\begin{array}{l}\text { VII } \\
\text { SEMESTER }\end{array}$} & Count & 1 & 28 & 9 & 38 \\
\hline & & $\%$ within the Semester & $2,6 \%$ & $73,7 \%$ & $23,7 \%$ & $100,0 \%$ \\
\hline & \multirow{2}{*}{$\begin{array}{l}\text { VIII } \\
\text { SEMESTER }\end{array}$} & Count & 1 & 15 & 14 & 30 \\
\hline & & $\%$ within the Semester & $3,3 \%$ & $50,0 \%$ & $46,7 \%$ & $100,0 \%$ \\
\hline \multirow{2}{*}{\multicolumn{2}{|c|}{ Total }} & Count & 5 & 210 & 74 & 289 \\
\hline & & $\%$ within the Semester & $1,7 \%$ & $72,7 \%$ & $25,6 \%$ & $100,0 \%$ \\
\hline
\end{tabular}


W. Cervera-Flores et al. / Advances in Science, Technology and Engineering Systems Journal Vol. 6, No. 1, 178-183 (2021)

\begin{tabular}{|l|r|r|r|}
\hline & \multicolumn{1}{|c|}{ Value } & gl & $\begin{array}{c}\text { Asymptotic significance } \\
\text { (bilateral) }\end{array}$ \\
\hline Pearson's Chi-square & $24,344^{\mathrm{a}}$ & 10 &, 007 \\
\hline Likelihood ratio & 22,625 & 10 &, 012 \\
\hline Linear by linear association & 4,130 & 1 &, 042 \\
\hline $\mathrm{N}^{\circ}$. of valid cases & 289 & & \\
\hline
\end{tabular}

a. 6 cells $(33.3 \%)$ have expected a count less than 5 . The minimum expected count is .52 .

In Table II, empathy is related to the semester of study of nursing students, in which it was determined with the Pearson chisquare test $\left(\mathrm{X}^{2}\right)$, the level of significance of the test obtained a value of $0.52(\mathrm{p}>0.05)\left(\mathrm{X}^{2}=24.344 ; \mathrm{df}=10\right)$. Therefore, a hypothesis of association between variables is not rejected, thus proving that there is a relationship between empathy and the semester of study of nursing students.

\section{Discussion}

In this study, we raise the issue of empathy is raised from the point of view of professional nursing training, where the level of empathy in nursing students who attend clinical practices at the Universidad de Ciencias y Humanidades, 2019 is assessed.

Regarding the level of empathy in nursing students who attend clinical practices of the Universidad de Ciencias y Humanidades, 2019, the medium level predominated followed by the high and low. These results may be because students have difficulty being able to understand or feel what the other person is experiencing.

It should be noted that the previous research work on the Empathy study were of different sociodemographic characteristics, the study in [3], the author indicates that the results of empathy were given by the different characteristics such as sex, academic year, academic performance, where the female sex showed high levels of empathy. Where empathy can change as the student progresses in their study plan. In [7], the author mention that the decrease in empathy is influenced by the absence of good teachers, the increased pressure for activities, long hours of service and evaluations in students, can lead them away from feelings of human problems and have a lack of opportunities to manage their emotions. Given the aforementioned, the nursing student can be related to their emotions, although it is true that empathy is not only based on doing a good job but, the way that the emotions are going to be applicated in this situation, it is very important to know that emotions have an important role in the students since they are in full formation and need the emotional maturity that allows them to perform humanized care, this means that it is not only enough to perform academically, because it would only enable their cognitive abilities, and to develop their emotional skills in a successful way, it is necessary to have training for it, so that the nursing students themselves carry out their humanized care at the time of carrying out their clinical practices.

Regarding the level of empathy in its dimension perspective taking in nursing students who attend clinical practices of the Universidad de Ciencias y Humanidades, 2019, the high level predominated followed by the medium and low. The perspective taking dimension refers to cognitive flexibility, understanding mood states, having good communication and interpersonal relationships with the patient. In [8], the author mentioned that students were concerned with learning about the process of conscious or consciously driven perspective taking and practicing self-awareness to help identify and then put aside biases and beliefs about health risk behaviors allowing better patient care. In [11], the authors indicate that empathy in a quality with great cognitive predominance, where understanding is more important. Since in this way, the patient's pain can be understood to show adequate communication and support, where the nurse-patient relationship will be strengthened. That is why having the ability to understand the patient's pain will be related to motivational factors in academic nursing training.

Regarding the level of empathy in its dimension compassionate care in nursing students who attend clinical practices at the Universidad de Ciencias y Humanidades, the low level prevailed followed by the medium and high levels, where this dimension was the most affected. The compassionate care dimension refers to the emotional states of others, literally feeling the person's pain. It originates from primitive parts of the brain that allow to feel quickly without thinking deeply. Compassion has global implications for nursing care. However, patients report that nurses do not provide compassionate care. Nursing education has been examined on the impact training can have on student compassion as there is a shortage of interventions aimed at teaching compassion to nursing students [12]. In [6], the authors mention the need for high empathic results, since emotional understanding is needed, listening to the patient's concerns so that it can alleviate its anguish thanks to the emotional expression of the nurse. That is why the study in [8], the authors indicated that the students said that it is important to listen to the stories of the patients, it was revealing as the stressors related to care and their impact on selfcare. Patient feedback made it easier for students to better understand and take ownership of their risky health behavior.

Regarding the level of empathy in its dimension, ability to put yourself in the patient's place in nursing students who attend clinical practices of the Universidad de Ciencias y Humanidades, 2019, the medium level prevailed followed by the low and high. The dimension of putting yourself in the patient's place refers to feel not only how other people feel, but also to know what they need from you. It involves putting yourself in the other's shoes, examining issues from their perspective, trying to think and feel as the other would. Lack of communication produces a loss of 
empathy and understanding between people, which translates into bad humor, fights, and an atmosphere of tension. Despite the burdens it has on the journey, it must not forget that others also have their own problems. Listening, dialoguing, understanding and helping are just some of the actions laden with value that can improve coexistence between people and allow to live in a more peaceful society [13].

Regarding the level of empathy in nursing students who attend clinical practices at the Universidad de Ciencias y Humanidades, 2019, studies carried out in [14], they concludes that women score significantly more than men in fantasy, empathic concern and personal discomfort.

In [15], the authors showed that women are more empathetic than men. This was attributed to an increased ability for perspective taking and compassionate attention, a situation that can be explained by social and biological factors. Among social factors, stereotypes attribute to women greater emotional sensitivity, concern for social aspects, a tendency to care for children and the elderly people, and greater ability to perceive feelings and non-verbal language.

In [7], they mentioned that the female sex has greater empathy than the male sex. This is due to the brain structure, where the nerve fibers between the two hemispheres perform better information transfer in communication and empathy, which occurs in the case of women. This would also explain the synchronization they have with the emotions expressed in non-verbal language with the patient.

The implementation of empathy education in the nursing professional training process brings good results. A systematic review in [16], titled "A systematic review of the effectiveness of empathy education for undergraduate nursing students," they indicate that in 23 studies of empathy education in undergraduate education in nursing, practical improvements in empathy were demonstrated. In all of them, interventions based on interview and experimental simulations were carried out, focusing on vulnerable patients.

\section{Conclusions}

It is concluded that the level of empathy in nursing students have been high, it could be specified that as students' progress academically, they tend to increase their empathy, depending on how the students can express themselves regarding their academic performance either theory or practical.

It is concluded that to have a high level of empathy, it is not only requires having a good academic ability, but also having a good ability to show emotions during clinical practices to provide self-confidence and gain the confidence of the patient during their care.

It is concluded that within the established dimensions of the research variable, in terms of the compassionate care dimension, an improvement program is required in terms of their professional training so that students can carry out compassionate care when performing their clinical practices.

As a future work, it is important to keep in mind that in universities there must be student nursing programs that allow them to benefit from their own empathic skills, so students could choose to have more knowledge and, at the same time, express their emotions through methods that allow to feel safe and have confidence in themselves when performing their clinical practices so that they are able to resolve any situation in patient care.

\section{Recommendations}

Regarding empathy in nursing students who attend clinical practices of the Universidad de Ciencias y Humanidades, 2019, the medium level predominated, followed by the high and low. It is suggested to the university authorities that activities be established to encourage students to have a good comprehensive education, in which the student can be involved in various topics in which the student can develop socially.

Regarding the empathy dimensions in all of them, the high level prevailed in the perspective taking dimension, it is suggested to the university authorities that students be fostered capacities in which they can distinguish when carrying out their clinical practices.

Training with the knowledge that the students could get a positive interaction with the people who will provide their care, involving both the faculty and the health institutions in which they will carry out their clinical practices.

It is suggested that, in future studies, a relationship between other variables linked to empathy be involved or exist, so that this problem can be better understood.

It is suggested to develop studies with qualitative or mixed approaches to complement the understanding of empathy in nursing students.

\section{Conflicts of Interest}

The authors declare no conflict of interest.

\section{References}

[1] U. Philadelphia, U. Jefferson, Jefferson Scale of Empathy. Center for Research in Medical Education and Health Care, Sidney Kimmel Medical College, 2019.

[2] H. Rozengway, A. García, I. Vallecillo, "Niveles de empatía según la escala de Jefferson en estu - diantes de Medicina, Enfermería y Odontología de Honduras.," Rev. Cient. Cien. Med., 19(2), 14-19, 2016.

[3] M. Madera, L. Tirado, F. González, "Factores relacionados con la empatía en estudiantes de Enfermería de la Universidad de Cartagena.," Enfermeria Clinica, 5(26), 282-289, 2016, doi:10.1016/j.enfcli.2016.06.004.

[4] P. Montanari, C. Petrucci, S. Russo, I. Murray, V. Dimonte, L. Lancia "Psychometric properties of the Jefferson Scale of Empathy-Health Professional Student's version: An Italian validation study with nursing students.," Nursing and Health Sciences, 17(4), 483-491, 2015, doi:10.1111/nhs. 12221 .

[5] J. Kim, "Factors influencing nursing students' empathy.," Korean Journal Of Medical Education, 30(3), 229-2236, 2018, doi:10.3946/kjme.2018.97.

[6] M. Giménez, S. Avivar, V. Prado, "Niveles de empatía en una muestra de enfermeras españolas.," Calidad de Vida y Salud, 9(2), 120-130, 2016.

[7] M. Montilva, M. García, A. Torres, M. Puertas, E. Zapata, "Empatía según la escala de Jefferson en estudiantes de Medicina y Enfermería en Venezuela.," Investigación En Educación Médica, 4(16), 223-228, 2015, doi:10.1016/j.riem.2015.04.006.

[8] M. Lobchuk, G. Halas, C. West, N. Harder, Z. Tursunova, C. Ramraj, "Development of a novel empathy-related video-feedback intervention to improve empathic accuracy of nursing students: A pilot study.," Nurse Education Today, 46, 86-93, 2016, doi:10.1016/j.nedt.2016.08.034.

[9] C. Fernández, P. Baptista, Metodología de la Investigación. 6ta ed. México: Mc Graw-Hill/Interamericana., 2015.

[10] A. Garza, J. González, S. Tavita, F. Rodriguez, M. Hojat, "Validación de la Escala de Empatia Médica de Jefferson en Estudiantes de Medicina Mexicanos.," Salud Mental, 28(5), 57-63, 2005. 
[11] J. Yu, M. Kirk, "Measurement of empathy in nursing research: Systematic review.," Journal of Advanced Nursing, 64(5), 440-454, 2008, doi:10.1111/j.1365-2648.2008.04831.x.

[12] M. Durkin, R. Gurbutt, J. Carson, "Qualities, teaching, and measurement of compassion in nursing: A systematic review.," Nurse Education Today, 63, 50-58., 2018, doi:10.1016/j.nedt.2018.01.025.

[13] G. Karayiannis, E. Papastavrou, A. Farmakas, H. Tsangari, M. Noula, Z. Roupa, "Exploration of empathy in Cyprus nursing and health care students: A mixed method study.," Nurse Education in Practice, 42, 102686, 2020, doi:10.1016/j.nepr.2019.102686.

[14] V. Díaz, G. Muñoz, N. Duarte, M. Reyes, S. Caro, A. Calzadilla, L. Alonso, "Empatía en estudiantes de enfermería de la Universidad Mayor, Sede Temuco, IX región, Chile.," Aquichan, 14(3), 388-402, 2014, doi:10.5294/aqui.2014.14.3.9.

[15] G. Parra, R. Cámara, "Nivel de empatía médica y factores asociados en estudiantes de medicina.," Investigación En Educación Médica, 6(24), 221227, 2017, doi:10.1016/j.riem.2016.11.001

[16] T. Levett, R. Cant, S. Lapkin, "A systematic review of the effectiveness of empathy education for undergraduate nursing students.," Nurse Education Today, 75, 80-94, 2019, doi:10.1016/j.nedt.2019.01.006. 